\title{
A special issue on knowledge and competence management: Developing Enterprise solutions
}

\author{
José Braga de Vasconcelos ${ }^{1} \cdot$ Chris Kimble $^{2}$ - Álvaro Rocha ${ }^{3}$
}

Published online: 4 November 2016

(C) Springer Science+Business Media New York 2016

\section{Introduction}

In a commercial environment, where downsizing, reengineering, restructuring and high rates of organisational turnover are common, businesses have recognised how easy it is to lose a vital element of their intellectual property: organisational knowledge (Hildreth et al. 2000). An organization's knowledge is built upon the experience of the people that make up the organization and the lessons they learn. In the current knowledge-based economy, the effective management of this knowledge is a significant challenge (Wang and Wang 2012); people are often unaware of the resources that lie 'hidden' in the heterogeneous knowledge repositories found inside large, modern, international organizations (Dzbor et al. 2000).

The central task for such organisations is to deal with their knowledge resources effectively, however, this is particularly true for what are now called knowledge intensive organisations (Alvesson 2004). These organisations and related enterprise solutions employ highly skilled staff, knowledge workers, whose role is essentially one of problem solving.

José Braga de Vasconcelos

jose.braga.vasconcelos@uatlantica.pt

Chris Kimble

chris.kimble@kedgebs.com

Álvaro Rocha

amrocha@dei.uc.pt

1 Universidade Atlântica, Barcarena, Portugal

2 KEDGE Business School and Université Montpellier, Talence, France

3 University of Coimbra, Coimbra, Portugal
Solving problems in such organisations involve complex, knowledge-intensive tasks such as dealing with abstraction and uncertainty or recognising patterns of organisational behaviour. Decisions often need to be taken in a dynamic work environment and based on data retrieved from several organisational information sources (Vasconcelos et al. 2007).

In knowledge intensive organisations, organizational knowledge is a product of the expertise, experience and skills of the individuals and workgroups that make up the organisation (Starbuck 1992). This knowledge can be stored in individual's minds, explicitly encoded and documented in corporate information systems, or implicitly embedded in organisational culture, rituals, policy and procedures (Alvesson 1995). To be effective workgroups in such organizations must not only seek to exploit examples of best practice (O’Dell and Grayson 1998), improve their efficiency (Zander and Kogut 1995), and contribute to overall organisational learning (Starbuck 1992), they also need to manage their existing skills effectively (Hansen et al. 1999), create mechanisms to elicit ideas and innovations (Hertog 2000), and identify new sources of information (Davenport et al. 1996).

However, like other organizations, knowledge intensive organizations also face restructuring and high rates of personnel turnover that can lead to problems of knowledge loss (Argote 1999) and knowledge retention (Olivera 2000; ElDiraby and Zhang 2006). Knowledge management initiatives seek to promote the retention, sharing and reuse of knowledge within an organization to achieve superior organizational performance (Alavi and Leidner 2001; Lesser and Storck 2001). Knowledge management strives to bring together various techniques for managing a shared and organized pool of organizational knowledge (Zack 1999). If successful, knowledge management should allow groups to coordinate their activities and share knowledge across time, function, discipline, and business activities - despite the fact that this 
knowledge may be geographically distributed and stored in a variety of different representations, (Vasconcelos et al. 2000).

However while the motivations behind knowledge management may appear clear, there are differences of opinion about the means by which to achieve them. The literature on knowledge management tends to divide along two lines (Grover and Davenport 2001; Edgar Serna 2012). The first focuses on capturing 'explicit' knowledge, codifying it and storing it in repositories for later reuse, whereas the second focuses on people and communities as sources of 'tacit' knowledge. As computers are simply data processing machines, codification is the only way to make them act as if they are able to store knowledge (Kimble 2013); consequently, the former approach tends to rely on computer-based repositories for storage and techniques borrowed from artificial intelligence for retrieval (Liebowitz 2001). The latter approach tends to be less technologically focused with computers simply acting as facilitators or channels of communication in what is essentially a person-to-person exchange (Chu et al. 2012).

As has been noted before, in reality, all knowledge management initiatives deal with both tacit and codified knowledge (Hildreth and Kimble 2002). Consequently it is of no surprise that in this special issue, we can find instances of both. For example Allal-Chérif et al. (2016) and Bououd et al. (2016) focus principally on the role of people and communities on managing knowledge, whereas Kimble et al. (2016) and Sánchez-Segura et al. (2016) focus mainly on codified knowledge.

The concepts of knowledge and competencies are closely related (Hellström et al. 2000; Lindgren and Wallström 2000; Lindgren et al. 2004) and competence management practices are widely used in knowledge intensive organisations (Vasconcelos et al. 2003). Competencies are the measurable characteristics of a person that are required to perform some specified task in a particular work situation (Klendauer et al. 2012); thus being able to manage competencies effectively is closely linked to superior performance as competencies represent the knowledge, skills and behaviors that contribute to a firms success (Prahalad and Hamel 1990). Competence management aims to make better use of human skills and knowledge (Vasconcelos et al. 2003; García-Barriocanal et al. 2012).

The construction of reliable descriptions of competencies, specifically the creation of consensual models and taxonomies to represent corporate competencies, are significant organizational and design challenges, both within the workplace and across the whole organization (Abel 2008). Over the past few decades, new research topics have emerged and new competencies have been developed in various knowledge domains (Carayannis 1999; Tarasov et al. 2007; García-Barriocanal et al. 2012). Trends in management and web techniques, such as knowledge acquisition and elicitation, competency mapping methods, enterprise web management and semantic web technologies, are shaping the companies of the future (Vasconcelos et al. 2000; Vasconcelos et al. 2003).

Some examples of these approaches can be found in this special issue. For example Lacheheub and Maamri (2016) look at creating intelligent business processed using on cloud computing and multi-agent systems while Kimble et al. (2016) describe a system based on an ontology-driven framework.

\section{Development of the special issue}

The goal of this special issue is to bring together these the two fields of knowledge and competence management by drawing on papers from researchers, professionals, and practitioners to present recent work in the field. In it, we present both the research challenges and the practical outcomes of applying knowledge management techniques to competence management in a corporate setting. This special issue also aims to show the relevance of research and enterprise approaches on competence management in the context of knowledge intensive organizations.

Most of the manuscripts are extended versions of selected papers from the WorldCIST'15 - 3rd World Conference on Information Systems and Technologies, which was held at Ponta Delgada, Azores, Portugal. The WorldCIST conferences have become an important forum for researchers and professionals to exchange ideas and experiences about research problems and corporate solutions related to information systems, technologies, and computer science in general.

The ten papers in this special issue include surveys, literature reviews and case studies as well as articles that focus more on the design and implementation of knowledge and competence management tools. The application areas include education, manufacturing industry and financial services. The topics cover games, knowledge engineering, ontologies and semantic web technologies, collaborative working and learning, and cost management.

\section{Papers in the special issue}

In 'Uncovering Hidden Process Assets: A Case Study', Sánchez-Segura et al. (2016), argue that the IT industry is not making the best use of its intellectual capital, such as process assets - the knowledge used to describe, implement and improve processes - and provide a classification scheme that companies can use to identify such assets. Their article presents a case study of two South American SMEs where the chief executive and chief operations officer used their classification scheme to identify a number of process assets that had not previously been recognized. 
The world of higher education is becoming increasingly internationalized. Based on the documentation for courses from the Institute of Accounting and Administration of Porto (ISCAP/IPP), Gonçalves et al. (2016) introduce a model for identifying and classifying competencies and learning outcomes in higher education - the MICRA model. The model provides an organized and systematic method for classifying course units; the article shows how the model can be applied to Computer Science Course Units of the Accounting and Business Administration degree at ISCAP/IPP.

Gamification - the use of game-like elements in non-game activities - is said to increase participants' motivation and engagement. Zimmerling et al. (2016), present a framework to integrate gamification into cost engineering, which they claim provides a systematic approach to managing the knowledge and competencies linked cost reduction measures throughout the life cycle of products. In addition to describing the framework, their article reports on twenty interviews in eight German and Austrian high-tech manufacturing companies which lead to the conceptual model upon which the framework was based.

Cloud computing and multi-agent systems have the potential to construct new business processes in innovative and cost efficient ways. In their paper 'Towards a Construction of an Intelligent Business Process Based on Cloud Services and Driven by Degree of Similarity and QoS', Lacheheub and Maamri (2016) argue that knowledge and competence management tends to focus on resource allocation and can have a positive impact on costs. Their paper describes an approach to constructing business processes based on the principles of competence and knowledge management, which identifies services that offer the same functionality and classifies them according to their similarity and their quality of service.

In 'Employee Knowledge Profiles - a Mixed-Research Methods Approach', Sousa and González-Loureiro (2016) provide a comparative case study of the role of knowledge management in two different organizations. Using an action research methodology, they identify several different knowledge profiles - innovators, integrators, organizers, and facilitators - and analyze their contribution to innovation. They show how the integration of knowledge through knowledge sharing routines and promotion of collaborative activities can boost innovation and argue that companies must pay particular attention to how knowledge integration is incorporated into organizational routines so that it becomes part of the organizational culture.

How can codified knowledge in computer based knowledge management systems be used to help manage competences in knowledge intensive organizations? In 'Competence Management in Knowledge Intensive Organizations using Consensual Knowledge and Ontologies', Kimble et al. (2016) examine organizations whose activities are based on the transfer, recombination, and adaptation of existing knowledge - knowledge intensive organizations. They explore the issues associated with the use of tacit and codified knowledge in such organizations and describe the architecture of a knowledge management system based on an ontology-driven framework that supports the management of competencies in a structured way.

Charband and Jafari Navimipour (2016) present a systematic literature review of online knowledge sharing literatures from 2009 up to the end of 2015. They found 348 papers; these were reduced to 251 selected studies that were then analyzed to reveal the state-of-the-art with regard to knowledge sharing in online environments. They look at four categories in which knowledge sharing plays a particularly role: online environments, supply chain management, teamwork in projects, and education, and outline topics for future research in these areas.

As with Zimmerling et al. (2016), Allal-Chérif et al. (2016) look at the link between games and competence management. They explore how so-called serious games can improve knowledge and competence management in the context of human resources management inside large organizations. Using the SECI model from Nonaka as their conceptual framework, the authors analyze the performance of three different serious games developed in three separate financial organizations in three different countries. They present a sevenstep development process for the creation of serious games and show how serious games can contribute to each of the four phases of the SECI model.

As the rate at which firms develop new products increases, it has become ever more crucial to enhance the absorptive capability of firms. In 'Exploring the Antecedents and Consequences of Technology and Knowledge Integration Mechanisms in the Context of NPD', Chang et al. (2016) use structural equation modeling to analyze 394 responses to a questionnaire distributed to general managers in January 2015. The results suggest that firms need to establish interaction to use external knowledge in new product development, and that this can be achieved by providing a friendly environment that encourages employees to share their knowledge.

3D virtual worlds appear to be promising tools for collaboration and knowledge sharing. In 'Impact of Object Manipulation, Customization and Social Loafing On Competencies Management in 3D Virtual Worlds', Bououd et al. (2016) present a study of 144 users of 3D virtual worlds that explores the effect that both the unique characteristics of the medium and personal attitudes can have on knowledge sharing and competence management. The results suggest that social loafing, the tendency to let others in the group do the work, has a significant negative effect on knowledge sharing while object manipulation and customization provide only a small moderating influence.

To conclude, we would like to thank all participants of WorldCIST 2015; in particular we would like to thank the 
WorldCIST program committee members and the reviewers for this special issue of Information Systems Frontiers for their dedication and hard work. We hope this special issue will stimulate your interest in this area and spur you on to engage in further research in this area.

\section{References}

Abel, M.-H. (2008). Competencies management and learning organizational memory. Journal of Knowledge Management, 12(6), 15-30.

Alavi, M., \& Leidner, D. E. (2001). Knowledge management and knowledge management systems: conceptual foundations and research issues. [review]. MIS Quarterly, 25(1), 107-136.

Allal-Chérif, O., Bidan, M., \& Makhlouf, M. (2016). Using serious games to manage knowledge and competencies: the seven-step development process. Information Systems Frontiers, 18(6). doi:10.1007/s10796-016-9649-7.

Alvesson, M. (1995). The Management of Knowledge-Intensive Companies. Berlin: Walter de Gruyter.

Alvesson, M. (2004). Knowledge work and knowledge-intensive firms. Oxford: Oxford University Press.

Argote, L. (1999). Organizational learning: Creating, Retaining and transferring knowledge: Kluwer academic.

Bououd, I., Skandrani, S. R., Boughzala, I., \& Makhlouf, M. (2016). Impact of object manipulation, customization and social loafing on competencies management in 3D virtual worlds. Information Systems Frontiers, 18(6). doi:10.1007/s10796-016-9655-9.

Carayannis, E. G. (1999). Fostering synergies between information technology and managerial and organizational cognition: The role of knowledge management. Technovation, 19(4), 219-231.

Chang, H. H., Tsai, Y.-C., Fu, C.-S., Chen, S.-H., \& De Peng, Y. (2016). Exploring the antecedents and consequences of technology and knowledge integration mechanisms in the context of NPD. Information Systems Frontiers, 18(6). doi:10.1007/s10796-016-9629-y.

Charband, Y., \& Jafari Navimipour, N. (2016). Online knowledge sharing mechanisms: a systematic review of the state of the art literature and recommendations for future research. Information Systems Frontiers, 18(6). doi:10.1007/s10796-016-9628-z.

Chu, M.-T., Khosla, R., \& Nishida, T. (2012). Communities of practice model driven knowledge Management in Multinational Knowledge Based Enterprises. Journal of Intelligent Manufacturing, 23(5), 1707-1720.

Davenport, T. H., Jarvenpaa, S. L., \& Beers, M. C. (1996). Improving knowledge work processes. Sloan Management Review, 37(4), 53-65.

Dzbor, M., Parlic, J., \& Parlic, M. (2000). Knowledge Management in a Distributed Organization. KMI Technical Report: The Open University.

Edgar Serna, M. (2012). Maturity model of knowledge Management in the Interpretativist Perspective. International Journal of Information Management, 32(4), 365-371.

El-Diraby, T., \& Zhang, J. (2006). A semantic framework to support corporate memory management in building construction. Automation in Construction, 15(4), 504-521.

García-Barriocanal, E., Sicilia, M.-A., \& Sánchez-Alonso, S. (2012). Computing with competencies: modelling organizational capacities. Expert Systems with Applications, 39(16), 12310-12318.

Gonçalves, M. J. A., Rocha, Á., \& Cota, M. P. (2016). Information management model for competencies and learning outcomes in an educational context. Information Systems Frontiers, 18(6). doi:10.1007 /s10796-016-9623-4.

Grover, V., \& Davenport, T. H. (2001). General perspectives on knowledge management: fostering a research agenda. Journal of Management Information Systems, 18(1), 5-21.
Hansen, M. T., Nohria, N., \& Tierney, T. (1999). What's your strategy for managing knowledge? Harvard Business Review, 77(2), 106-116.

Hellström, T., Kemlin, P., \& Malmquist, U. (2000). Knowledge and competence Management at Ericsson: decentralization and organizational fit. Journal of Knowledge Management, 4(2), 99-110.

Hertog, P. D. (2000). Knowledge-intensive business services as Coproducers of innovation. International Journal of Innovation Management, 4(04), 491-528.

Hildreth, P., \& Kimble, C. (2002). The duality of knowledge. Information Research, 8(1). http://informationr.net/ir/8-1/paper142.html

Hildreth, P., Kimble, C., \& Wright, P. (2000). Communities of practice in the distributed international environment. Journal of Knowledge Management, 4(1), 27-37.

Kimble, C. (2013). Knowledge management, codification and tacit knowledge. Information Research, 18(2). http://informationr. net/ir/18-2/paper577.html

Kimble, C., de Vasconcelos, J. B., \& Rocha, Á. (2016). Competence management in knowledge intensive organizations using consensual knowledge and ontologies. Information Systems Frontiers, 18(6). doi:10.1007/s10796-016-9627-0.

Klendauer, R., Berkovich, M., Gelvin, R., Leimeister, J. M., \& Krcmar, H. (2012). Towards a competency model for requirements analysts. Information Systems Journal, 22(6), 475-503.

Lacheheub, M. N., \& Maamri, R. (2016). Towards a construction of an intelligent business process based on cloud services and driven by degree of similarity and QoS. Information Systems Frontiers, 18(6). doi:10.1007/s10796-016-9625-2.

Lesser, E. L., \& Storck, J. (2001). Communities of practice and organizational performance. IBM Systems Journal, 40(4), 831-841.

Liebowitz, J. (2001). Knowledge management and its link to artificial intelligence. Expert Systems with Applications, 20(1), 1-6.

Lindgren, R., \& Wallström, C. (2000). Features Missing in Action: Knowledge Management Systems in Practice. Paper presented at the Proceedings of the 8th European Conference on Information Systems (ECIS 2000), Wienna, Austria, July 3-5

Lindgren, R., Henfridsson, O., \& Schultze, U. (2004). Design principles for competence management systems: a synthesis of an action research study. MIS Quarterly, 28(3), 435-472.

O'Dell, C., \& Grayson, C. J. (1998). If only We knew what We know: identification and transfer of internal best practices. California Management Review, 40(3), 154-174.

Olivera, F. (2000). Memory Systems in Organizations: an empirical investigation of mechanisms for knowledge collection, storage and access. Journal of Management Studies, 37(6), 811-832.

Prahalad, C. K., \& Hamel, G. (1990). The Core competence of the corporation. Harvard Business Review, 68(3), 79-91.

Sánchez-Segura, M.-I., Ruiz-Robles, A., \& Medina-Dominguez, F (2016). Uncovering hidden process assets: a case study. Information Systems Frontiers, 18(6). doi:10.1007/s10796-0169622-5.

Sousa, M. J., \& González-Loureiro, M. (2016). Employee knowledge profiles - a mixed-research methods approach. Information Systems Frontiers, 18(6). doi:10.1007/s10796-016-9626-1.

Starbuck, W. H. (1992). Learning by knowledge-intensive firms. Journal of Management Studies, 29(6), 713-740.

Tarasov, V., Albertsen, T., Kashevnik, A., Sandkuhl, K., Shilov, N., \& Smirnov, A. (2007). Ontologybased competence management for team configuration. In Holonic and Multi-Agent Systems for Manufacturing (pp. 401-410). Springer Berlin Heidelberg.

Vasconcelos, J., Kimble, C., Gouveia, F. R., \& Kudenko, D. (2000). A Group Memory System for Corporate Knowledge Management: An Ontological Approach. In 1st European Conference on Knowledge Management, Bled, Slovenia (pp. 91-99): MCIL.

Vasconcelos, J., Kimble, C., \& Rocha, Á. (2003). Organisational memory information systems: an example of a group memory system for the 
Management of Group Competencies. Journal of Universal Computer Science, 9(12), 1410-1427.

Vasconcelos, J., Gouveia, F. R., Kimble, C., \& Kudenko, D. (2007). Reasoning in Corporate Memory Systems: A Case Study of Group Competencies. In J. F. Schreinemakers \& T. M. V. Engers (Eds.), 15 Years of Knowledge Management (Vol. 3, Advances in Knowledge Management). Würzburg: Ergon.

Wang, Z., \& Wang, N. (2012). Knowledge sharing, innovation and firm performance. Expert Systems with Applications, 39(10), 8899-8908.

Zack, M. H. (1999). Developing a knowledge strategy. California Management Review, 41(3), 125-145.

Zander, U., \& Kogut, B. (1995). Knowledge and the speed of the transfer and imitation of organizational capabilities: an empirical test. Organization Science, 6(1), 76-92.

Zimmerling, E., Höflinger, P. J., Sandner, P. G., \& Welpe, I. M. (2016). A system framework for gamified cost engineering. Information Systems Frontiers, 18(6). doi:10.1007/s10796-016-9624-3.

José Braga de Vasconcelos is an adjunct professor of information systems and software engineering at the University Atlântica, Portugal where he is the Coordinator of the Master's Degree on Management Information Systems. He is also an invited Auxiliary Professor at the University Europeia (Laureate International Universities) in Lisbon. He holds a $\mathrm{PhD}$ in Computer Science at the University of York (UK) and a MSc on Management and Information Systems at the University of Minho (Portugal). He has written technical books and research papers about algorithms and data structures, software engineering, and knowledge management. The last edited book is about web programming. He also works as a consultant on knowledge management, software engineering, and information systems development.
Chris Kimble is an associate professor of strategy and technology management at KEDGE Business School Marseille, France; he is also affiliated to the MRM Laboratory at Université Montpellier, France. His broad field of research is the management of the fit between the digital and social worlds. He is the academic editor of Global Business and Organizational Excellence (Wiley), has produced a number of edited books, and has published articles in journals and conferences. Before moving to France, he lectured in the UK on information systems and management at the University of York, on information technology at the University of Newcastle, and was a researcher with both the Business School and the Department of Informatics at the University of Northumbria.

Álvaro Rocha is Professor of Information Systems at University of Coimbra and an invited Professor at University of Santiago de Compostela and at University of Vigo. He holds Habilitation in Information Systems and Technologies, $\mathrm{PhD}$ in Engineering and Management of Information Systems, and a MSc in Information Management. He is a senior researcher at the LIACC (Laboratory of Artificial Intelligence and Computer Science) and a collaborator researcher at the CINTESIS (Center for Research in Health Technologies and Information Systems). He is President of AISTI (Iberian Association for Information Systems and Technologies) and Vice-President of ADIPME (Association for the Development and Innovation in the Small and Medium Enterprises). He is also the Editor-in-Chief of the Software Engineering journal and the Editorin-Chief of the RISTI (Iberian Journal of Information Systems and Technologies). 